THE STORY OF MY CAMPAIGN 



\section{THE STORY OF MY CAMPAIGN The Civil War Memoir of Captain Francis T. Moore, Second Illinois Cavalry}
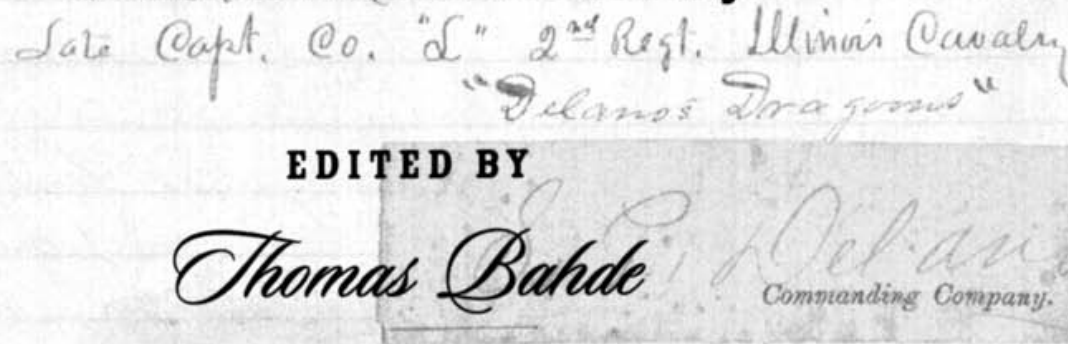

Compranding Company.

With a Foreword by Michael Fellman

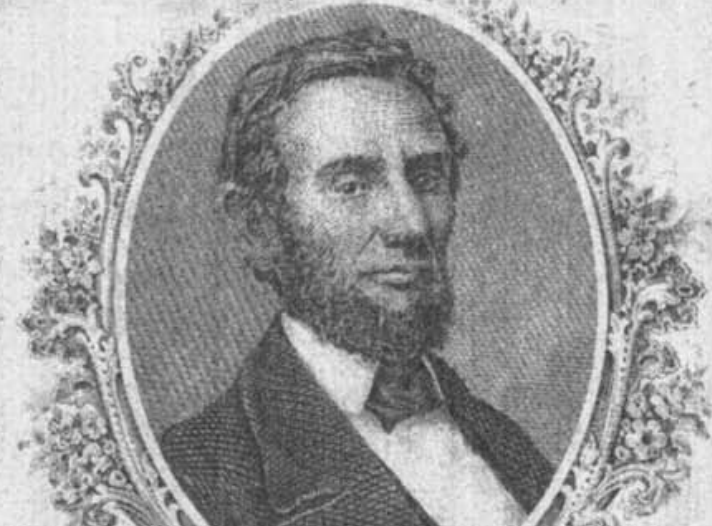

III NORTHERN ILLINOIS UNIVERSITX PRESS DeKalb 
(C) 2011 by Northern Illinois University Press

Published by the Northern Illinois University Press, DeKalb, Illinois 60115

All Rights Reserved

Design by Shaun Allshouse

Library of Congress Cataloging-in-Publication Data

Moore, Francis T., 1838-1912.

The story of my campaign : the Civil War memoir of Captain Francis T. Moore,

Second Illinois Cavalry/ edited by Thomas Bahde.

p. cm.

Includes bibliographical references and index.

ISBN 978-0-87580-441-5 (clothbound : acid-free paper)

1. Moore, Francis T., 1838-1912. 2. United States. Army. Illinois Cavalry Regiment, 2nd (1861-1865) 3. United States. Army-Military life-History-19th century. 4. SoldiersIllinois-Biography. 5. Illinois-History-Civil War, 1861-1865-Personal narratives.

6. United States-History-Civil War, 1861-1865 - Personal narratives. 7. United StatesHistory-Civil War, 1861-1865-Cavalry operations. 8. Illinois-History-Civil War, 1861-1865-Regimental histories. 9. United States-History-Civil War, 1861-1865Regimental histories. I. Bahde, Thomas William. II. Title.

E505.62nd.M66 2011

973.7'8092-dc23

[B]

2011016757

Title page image courtesy of Special Collections and University Archives,

San Diego State University Library \& Information Access 